\title{
Development of POGIL (Process Oriented Guided Inquiry Learning) Strategy based on Intertextual Learning of Acid-Base Concepts
}

\author{
Ilma Inaroh Azizah \\ Department of Chemistry Education \\ Indonesia University of Education \\ Setiabudi 229 Bandung 40154 Indonesia
}

\author{
Sri Mulyani* \\ Department of Chemistry Education \\ Indonesia University of Education \\ Setiabudi 229 Bandung 40154 Indonesia \\ *Corresponding author: srimulyani_upi@yahoo.co.id
}

\author{
Fitri Khoerunnisa \\ Department of Chemistry Education \\ Indonesia University of Education \\ Setiabudi 229 Bandung 40154 Indonesia
}

\begin{abstract}
The aim of this study is to develop the POGIL (Process Oriented Guided Inquiry Learning) strategy of acids and bases concepts based on intertextual learning. The strategy was designed to assist students mastery concepts by interrelating the chemistry phenomena and acid-base concepts on three level representations: macroscopic, submicroscopic, and symbolic. The development process was initiating by curriculum analysis, developing three level representations of acid-base concepts, designing POGIL strategy intertextual-based, preparing instrument to measure students's mastery concept, and POGIL aplication in a limited class. All instruments were judged by the experts (chemistry lecturers and teachers) in term of content validity. The results were considered valid by all validators with some improvements based on the validator's suggestions and expertise.
\end{abstract}

Keywords-Learning Strategy; Intertextual; POGIL; AcidBase; Concept Mastery

\section{INTRODUCTION}

Chemistry is one of the corner stone of science, technology, and industry thatremarkably contributes to living existence, especially to improve life quality [1], therefore, it is essential to learn chemistry comprehensively. Previous works showed that students have many problems on learning of chemistry concept. Additionally, chemistry is still considered to be one of difficult subjects due to the abstract nature of many chemistry concepts, inappropriate learning strategy and method, and understanding deficiency of chemistry representations (macroscopic, microscopic, and symbolic) either on textbook or other learning sources. Those problems potentially led to student's misconception [2-3].

On the other hand, acid-base theory is one of chemistry basic concepts since most of chemical reactions involve acidbase reactions [1]. Hence, it has been taught from primary level to the university [4-12]. Regarding to misconception phenomena on acid-base concept, Cross (1986) mentioned that around $47 \%$ and $14 \%$ of student's misconception were found for Bronsted-Lowry and Arrhenius theories, respectively. Additionally, Hawkes (in [11])mentioned that students were confused on applying acid-base theories (either Arrhenius or Bronsted-Lowry) on problem solving of acid-based concepts, for example, on determination of acid-base definition and properties. In particular, student conception of acid-base was still dominated by Arrhenius theory, where merely that the substances produced $\mathrm{OH}^{-}$and $\mathrm{H}^{+}$ions in water are considered as bases and acid, respectively. In contrast, most students did not use the Bronsted-Lowry theory to explain the properties of acids and bases[4]. Those results inferred that students faced learning difficultness and may lead tomisconception. Moreover, it is mentioned that there are two main sources of students' misconceptions: (1) teaching process at school and (2) intuition that influenced by the representations or superficial meanings of characters and symbols of chemistry [12], suggesting that chemistry learning strategies play crucial role on creating student's conception and/or misconception.

Meanwhile, intertextual in chemistry relates to interrelationship between chemistry phenomena and concepts by means of three level representations of chemistry i.e. macroscopic, submicroscopic, and symbolic level [13]. These representations can guide students to understand chemistry concept easily. Unfortunately, the application of three level representations on chemistry learning process was still infrequent

At the same time, POGIL (Process Oriented Guided Inquiry Learning) learning strategy developed by Moog and Hanson was designed to assist students in enhancing their concept mastery [14]. According to Nadelson [15], POGIL based chemistry learning strategy can facilitate students to learn science freely even through the alternative conception. Furthermore, this method can support students on connecting the macroscopic and microscopic phenomena to symbolic representation. Hence, it is worthwhile to conduct a research study about the development of POGIL strategy based on intertextual learning for acid-base concept. This study is 
conducted to the high school student which refers to the curriculum 2013 that implemented in Indonesia.

\section{RESEARCH METHOD}

This study was focused on development of POGIL strategy based on intertextual learning of acid-base, especially, Bronsted-Lowry theory. The development process was consisted of several stages i.e. (1) curriculum analysis to make the indicator of mastery concept, (2) analysis of acid-base concept from general chemistry textbooks to develop three representation levels of acid-base (i.e. macroscopic, submicroscopic, and symbolic), especially Bronsted-Lowry theory, (3) development of POGIL based on intertextual learning strategy (learning activities), (4) preparation of research instruments includes congruence tables of concept mastery indicatorswith basic competence of knowledge, concepts with the indicators of mastery concepts, learning activities with the POGIL strategies, and the aspect of mastery concept with learning activities, and 5) validation of instruments by the experts (chemistry lectures and teachers).

\section{RESULTS AND DISCUSSION}

According to the learning stages of POGIL, the early stages is orientation phase which provides the preliminary information of the subject that will be studied, the objectives as well as the learning outcomes. In this stage, the teacher provides some issues (phenomena) to encourage students motivation and interest on learning the subject. For example, here we serve the phenomena of cake dough expansion during baking process, where the baking powder (consist of sodium bicarbonate/ $\mathrm{NaHCO}_{3}$ and sodium dihydrogen phosphate/ $\mathrm{NaH}_{2} \mathrm{PO}_{4}$ ) were dissosiated as a result of heating. Since the cake dough contains water, it can be used as medium for $\mathrm{NaHCO}_{3}$ and $\mathrm{NaH}_{2} \mathrm{PO}_{4}$ to be ionized become $\mathrm{HCO}_{3}{ }^{-}$and $\mathrm{H}_{2} \mathrm{PO}_{4}^{-}$ions, respectively. These ions will react to form $\mathrm{HPO}_{4}{ }^{2-}$ and $\mathrm{H}_{2} \mathrm{CO}_{3}$ species. Hereafter, $\mathrm{H}_{2} \mathrm{CO}_{3}$ will be quickly dissociated to $\mathrm{CO}_{2}$ and $\mathrm{H}_{2} \mathrm{O}$ gases, consequently, expanding the cake dough volume. Indeed, the reaction between $\mathrm{HCO}_{3}$ and $\mathrm{H}_{2} \mathrm{PO}_{4}^{-}$ionscan be classified as acid-base reaction. Moreover, in this stage, the teacher also guides students to remind the Arrhenius theory of acid-base which have been learned previously. Furthermore, students are given some questions, i.e "Could you explain the acid-base reaction between $\mathrm{HCO}_{3}^{-}$and $\mathrm{H}_{2} \mathrm{PO}_{4}^{-}$ions in term of Arrhenius theory?". This question triggered students to analyze the reactions that occur in $\mathrm{HCO}_{3}^{-}$and $\mathrm{H}_{2} \mathrm{PO}_{4}{ }^{-}$ions that can't be simply explained using Arrhenius theory, since there is no $\mathrm{OH}^{-}$ion involved in the chemical formula. It was found the the students were confused and difficult to determine the base component from those ions. Therefore, teacher suggests that another concept (theory) is required to explain this reaction. Subsequently, students are asked to sit within the group that has been determined by the teacher randomly or heterogeneous (combination of upper and lower levels) where each group consists of three to four members. Based on the POGIL learning characteristics, each member within the group has different role play, where they can be either as manager, recorder, spokesperson, or analyzer strategy.

The next stage is exploration phase (includes observing, proposing and testing hypothesis, designing experiment- includes designing the experimental step and identifying variables, and doing experiment). Each student acquires the worksheet about Brønsted-Lowry theory based acid-base concept. In particular, the worksheet contains focus questions i.e. "Why Ammonia $\left(\mathrm{NH}_{3}\right)$ solution is alkaline?". The objective of question is to make students easier to find out the concept about Brønsted-Lowry theory based acid-base, because the alkaline properties from ammonia solution can not be directly explained using Arrhenius theory. In this stage, some students demonstrate the experiment to determine the properties of ammonia and sodium hydroxide solution using acid-base indicators such as BTB (Bromtymol Blue) and the lytmus paper. The experimentalresult provides the clues for student to make a hypothesize (the answer to the focus question in the worksheet). The expected hypothesis that is "Ammonia solution is alkaline due to producing the $\mathrm{OH}^{-}$ion" since this solution changed from colorless to blue after BTB addition, and the lytmus paper changed from red to blue. And then, some students are asked to check about the electrical conductivity in order to testing (confirm) their hypothesis. The electrical conductivy measurement demonstrates the ammonia solution is weak electrolyte since the lamp shows dim light and a few bubble around the electrodes can be observed. This means that few ions produced in this solution facilitate electron conduction in the outer circuit. The electrical properties of ammonia solution is a macroscopic representationo Brønsted-Lowry theory based acid-base. Furthermore, students observe the model 1 (Fig. 1) in order to find out the acid-base concept based on Bronsted-Lowry theory. The model 1 represents the symbolic level from the ionization of ammonia solution.

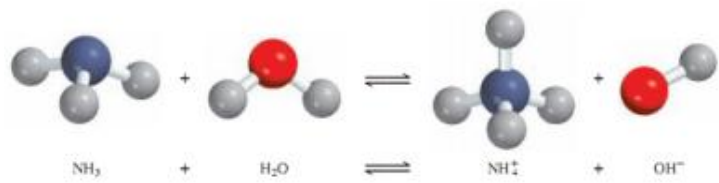

Fig. 1. The Model 1-Brønsted-Lowry Theory based Acid-Base Concept[16]

The next stage is the concept invention (formation phase), where the students are given some questions that require them to think critical and analytical on determination of acid-base components based on Brønsted-Lowry theory. Particularly, in the guided inquiry model, the learning activities are divided into several typesbased on the characteristic of POGIL questions (namely direct and convergent questions). The direct questions have an answer that only can be derived from the model. Through the given the direct questions, students are expected to be able to process the information presented in the model so they can answering questions related to the information and concepts to be learned.One of the example of direct questions is the changes in the $\mathrm{H}_{2} \mathrm{O}$ molecules before and after reacting with $\mathrm{NH}_{3}$ molecules, i.e., "Based on the observations, what ions are reduced from $\mathrm{H}_{2} \mathrm{O}$ to become $\mathrm{OH}$ ? In addition, what ionsare gained from $\mathrm{NH}_{3}$ so it turns $\mathrm{NH}_{4}{ }^{+}$?", by providing that question, students are expected to answer that when $\mathrm{H}_{2} \mathrm{O}$ turned into $\mathrm{OH}^{-}$ion it releases $\mathrm{H}^{+}$ion and also when $\mathrm{NH}_{3}$ turned into $\mathrm{NH}_{4}{ }^{+}$ion it accepts $\mathrm{H}^{+}$ion.

Furthermore, students are also given some kind of convergent questions to enhance the concept of mastery in the formation of the understanding on Brønsted-Lowry theory 
based acid-base concept. The convergent question is intended to assist students in making connections and getting a conclusion that cannot be obtained by direct question. One the example of convergent question is, "Why $\mathrm{H}_{2} \mathrm{O}$ which isneutral is transformed into $\mathrm{OH}^{-}$ion which has negatively charged? Instead why $\mathrm{NH}_{3}$ is neutral turned into $\mathrm{NH}_{4}^{+}$ions which has positively charged?".Based on these questions students are expected to answer that " $\mathrm{H}_{2} \mathrm{O}$ turned into $\mathrm{OH}^{-}$due to releasing the $\mathrm{H}^{+}$ion while $\mathrm{NH}_{3}$ turned into $\mathrm{NH}_{4}{ }^{+}$due to accepting $\mathrm{H}^{+}$ ion".

Next, students are given questions about the transfer of $\mathrm{H}^{+}$ ion occurs between $\mathrm{H}_{2} \mathrm{O}$ molecules (acts as acid) and $\mathrm{NH}_{3}$ molecules (acts as base). Through Model 1, students are expected to understand that the $\mathrm{H}^{+}$ion moves from $\mathrm{H}_{2} \mathrm{O}$ to $\mathrm{NH}_{3}$, or from acid to base. And then, students are required to complete the hiatus question as a mean for students to make inferences from the concepts that have been learned. This statement also connects submicroscopic and symbolic representation levels of acid-base definition according to Brønsted-Lowry theory. The answer from the hiatus questionactually gives a conclusion, where regarding to Bronsted-Lowry theory, acid is a particle that gives $\mathrm{H}^{+}$ion to the base, while the base is a particle that receives $\mathrm{H}^{+}$ion from the acid.

After forming the concept of Brønsted-Lowry acid-base, the next step is the formation of the concept of conjugate acidbase pairs through observations on the Model 2 (Fig.2).

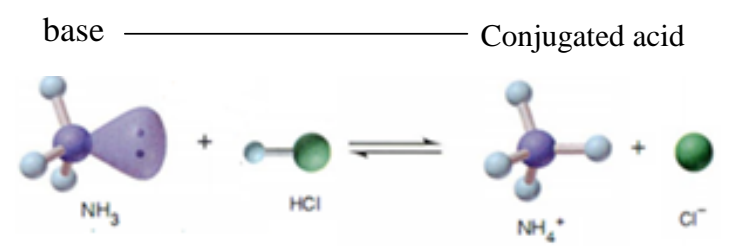

Fig. 2. Model 2-Acid Base Conjugate Pairs [17]

In the process of the concept formation, firstly, students must identify the acids and bases properties of all species exist in Model 2. Then, the students are given information of acidbase reaction that composed by two Brønsted-Lowry acid-base conjugate pairs $\left(\mathrm{NH}_{3}-\mathrm{NH}_{4}^{+}\right)$. Students are required to determine the other conjugate acid-base pairs in the reaction on model $2\left(\mathrm{HCl}\right.$ and $\left.\mathrm{Cl}^{-}\right)$. Through this model, students are guided to create the definition of the conjugate acid-base pair.

The next stage is the strengthening and expansion of concept, namely the application phase (involves the use of new knowledge in the exercises/problem solving). Students are given the questions of the phenomenon that occurs in thedoughexpansion by mean of baking powder. Through this question the teacher helps students to relate the concepts with the phenomenon given in the beginning of learning activities and to realize that the studied concept is really close todaily activities and provides benefits for them. In addition to the some questions of concept applications, there is also a problem solving. In this case, the question was related to acidbase reaction without water solvent, for instance, the reaction of pure sulfuric acid with salt. Through this question, students are expected to apply the concept acid-base according to Bronsted-Lowry theory in order to answer that question.
Interestingly, some misconceptions were found in this term, for example, "the ionization of polyprotic weak acid ( $\mathrm{HnX})$ is and is recognized as one step of the ionization reaction".

$$
\mathrm{H}_{2} \mathrm{SO}_{4}+\mathrm{Cl}^{-} \rightarrow \mathrm{HCl}+\mathrm{HSO}_{4}^{-}
$$

Finally, the last stage is the closing phase (reflection), where the students reflect on what they have learned and assess their performance by filling out their worksheet and doing selfassessment.

Moreover, the research instruments have high validity based on the experts (lecturers and teachers) judgement. Nevertheless,many comments and suggestions from the experts can be briefly summarized as follow:

(1) The macroscopic representation level of Brønsted-Lowry theory based acid-base concept should be shown by the picture of white baking powder and the ingredient content.

(2) The model 1 should not be labeled as acid and base. It is better to provide opportunity to studets to independently discover (following inquiry approach) the properties of acids and bases of each species from the reaction of $\mathrm{NH}_{3}$ and $\mathrm{H}_{2} \mathrm{O}$ molecules. Based on this suggestions, the label acids and bases in the model 1 was removed.

The following questions are the revised version after correction by the experts.

1. Based on experimental results, what is the acidity of $\mathrm{NH}_{3}$ solution?

2. List the solute and solvent components of $\mathrm{NH}_{3}$ solution.

3. If it is known that the acidity properties are affected by the acidity the solute of the solution, then determine the acidity properties of the solute in $\mathrm{NH}_{3}$ solution. (Write in the appropriate fields in the model 1)

4. In Brønsted-Lowry theorybased acid-base concept, if the solute is a base, then the solvent must be an acid. Vice versa, if the solute is an acid, then the solvent must be a base. What are the acidity properties of the solvent in $\mathrm{NH}_{3}$ solution? (Write in the appropriate fields in the model 1)

(1) It is better to provide the reaction equations in term of Lewis structure in order to facilitate students in determination of the ion charges. As well, the used of color variation for each species symbols will be helpful for students to easily distinguish which ions move from $\mathrm{H}$

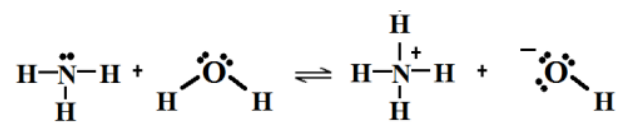

Fig. 3. Lewis Structure of $\mathrm{NH}_{3}$ and $\mathrm{H}_{2} \mathrm{O}$ reaction as Model 1 .

(2) Regarding to improvent of student thinking skill, the question of critical thinking was revised as follow:

a) How do the changes in $\mathrm{NH}_{3}$ after reacting with $\mathrm{H}_{2} \mathrm{O}$ ?

b) What happened to the charge change in $\mathrm{NH}_{3}$ after reacting with $\mathrm{H}_{2} \mathrm{O}$ ?

c) What particle causes $\mathrm{NH}_{3}$ turn into $\mathrm{NH}_{4}^{+}$?

d) How do the changes in $\mathrm{H}_{2} \mathrm{O}$ after reacting with $\mathrm{NH}_{3}$ ?

e) What happened to the charge change in $\mathrm{H}_{2} \mathrm{O}$ after reacting with $\mathrm{NH}_{3}$ ? 
f) What particle are reduced, which causes $\mathrm{H}_{2} \mathrm{O}$ turned into $\mathrm{OH}^{-}$?

g) How many particles are reduced from $\mathrm{H}_{2} \mathrm{O}$ thus changed into $\mathrm{OH}^{-}$and how many particles are gained from $\mathrm{NH}_{3}$ so it turns $\mathrm{NH}_{4}{ }^{+}$?

h) How is the transfer of particles that is occurred between $\mathrm{NH}_{3}$ and $\mathrm{H}_{2} \mathrm{O}$ molecules?

i) Based on the input field in model 1 , how the $\mathrm{H}^{+}$ion transfer that is occurred between the acid and base particles?

j) Based on the input field in model 1, according to the Brønsted-Lowry theory.

k) Create the definition of acid and base according to the Brønsted-Lowry theory.

\section{CONCLUSIONS}

Based on the results and discussion of development of POGIL strategy based on intertextual learning acid-base concept is derived the development of the worksheet and the design of learning activities using POGIL. The learning activities that have been developed in intertextual learning with POGIL strategy on acid-base concept involve the three representative levels of chemistry (macroscopic, submicroscopic and symbolic) into learning steps of POGIL.

Intertextual learning with POGIL strategy should be tested on students in the actual class to obtain student's mastery concepts and optimal improvement. Intertextual learning with POGIL strategy can be applied to other chemical concepts.

\section{References}

[1] P.I. Cetingul and O. Geban, "Understanding of acid-base concept by using conceptual change approach", H.U. Journal Of Education. Vol.29, 2005, pp.69-74.

[2] L. Cardellini, "Chemistry: why the subject is difficult?",Areas Emergentes De La Educacion Quimica, Vol.242, 2012, pp.: 1-6.

[3] M. Woldeamanuel, H. Atagana, and T.Engida, "What makes chemistry difficult?", African Journal of Chemical Education. Vol.4 (2), 2014, pp. $31-43$.
[4] M. Demerouti, M. Kousathana, G. Tsaparlis, "Acid-base equilibria part I. Upper secondary students' misconceptions and difficulties",The Chemical Educator. Vol.9(2), 2004, pp. 122-131.

[5] G. Demircioglu, A. Ayas, H. Demircioglu, "Conceptual change achieved through a new teaching program on acids and bases",Chemistry Education Research and Practice. Vol.6 (1), 2005, pp. 36-51.

[6] M. Drechsler, H. Schmidt, "Upper secondary school understanding of models used in chemistry to define acids and bases",Science Education Internatinal. Vol.16(1), 2005, pp. 39-53.

[7] T. Pinarbasi, "Turkish undergraduate students'misconceptions on acids and bases”, Journal of Baltic Science Education. Vol. 4(1), 2007, pp. 23 34.

[8] H.D. Barke, A. Hazari, S. Yitbarek, Misconceptions in chemistry: addressing perceptions in chemical education. Heidelberg: Springer, 2009.

[9] E.S. Halstead, A critical analysis of research done to identify conceptual difficulties in acid-base chemistry. Dissertation. School of Biochemistry, Genetics and Microbiology: University of KwaZulu-Natal, Pietermaritzburg, 2009.

[10] Z. Muchtar,"Analyzing of Students' Misconceptions on Acid-Base Chemistry at Senior High Schools in Medan". Journal Of Education And Practice. Vol.3(15), 2012, pp. 65-74.

[11] L. Tarhan andB.A. Sesen, "Jigsaw cooperative learning: acid-base theories". Chemistry Education Research and Practice. Vol.13, 2012, pp.307-313.

[12] M-H Chiu, J-W. Lin, and J-C.Liang, "Exploring mental models and causes of students' misconceptions in acids and bases", Taipei: National Taiwan Normal University, 2004.

[13] H.K. Wu, "Linking the microscopic view of chemistry toreal life experiences: intertextuality in a high school science classroom". Science Education. Vol.87, 2013, pp. 868-891.

[14] D.M. Hanson, Instructor's guide to process-oriented guided-inquiry learning. New York: Pacific Crest, 2006.

[15] E. C. Villagonzalo, "Process oriented guided inquiry learning: an effective approach in enhancing students' academic performance". Presented at the DLSU Research Congress. De La Salle University, Manila, Philippines. 2014.

[16] R. Chang and J. Overby, General chemistry: the essential concepts. Sixth Edition. New York: McGraw-Hill Companies, Inc, 2014.

[17] M.S.Silberberg, Principles of general chemistry. New York: The McGraw-Hill Companies, Inc, 2007. 